\title{
A imaterialização da marca: da economia da mercadoria à economia da transformação
}

The dematerialisation of the brand: from the commodity economy to the transformation economy

Carla Suzana Dias ${ }^{1}$

Ana Baptista ${ }^{2}$

Resumo: No mundo atual, as marcas vieram a reconhecer que o designe a produção de objetos representa apenas uma parte do seu negócio. Assim, esforçam-se por desenvolver com sucesso novas estratégias de marketing, como o branding baseado na experiência. Todavia, alguns autores apontam para a necessidade de a economia se basear em algo mais duradouro do que a memória que o serviço ou a experiência de uma marca possa despertar no público. Sustentam, portanto, a importância de se desenvolver a "economia da transformação". Neste artigo, discutimos o processo de imaterialização da marca e, consequentemente, a mudança do seu valor no mercado ao longo das últimas décadas. Apoiados em autores que pensam o mundo contemporâneo a partir da análise social, econômica ou das áreas da comunicação, como o marketing e o design, procuramos contribuir para a reflexão e o reconhecimento de questões emergentes que possam estar de acordo com as complexas demandas de um crescimento financeiro futuro.

Palavras-chave: marketing; comunicação; marca; experiência; economia da transformação.

1 Instituto Politécnico do Cávado e do Ave, ID+ Instituto de Investigação em Design, Media e Cultura / Polo IPCA, Barcelos, Portugal.

https://orcid.org/0000-0002-8641-1892. E-mail: cdias@ipca.pt

2 Queen Mary University of London (QMUL). Londres, Reino Unido.

https://orcid.org/0000-0002-9157-6464.E-mail: a.baptista@qmul.ac.uk 
Abstract: Currently, brands have been recognising that thinking about design and object production is a part of their business. Therefore, brands have been attempting to successfully develop new marketing strategies for the brand experience. However, some authors have been highlighting the need for an economy based on something more long lasting than what the memory of a service or experience of the brand causes in the public. Diverse authors argue for the development of the 'Transformation Economy'. In this article, we will discuss the process of brand dematerialisation, and thus the change of its economic value in the last decades. Our arguments will be supported on authors who think about the contemporary work from a social, economic and communicational perspectives. We aim at contributing to reflection and recognition of emerging questions which can be aligned with the complex challenges of the future financial growth. Keywords: marketing; communication; brand; experience; transformation economy. 
As circunstâncias quotidianas - já tratadas e aprofundadas em publicações anteriores (DIAS, 2017, 2018; DIAS e MOURA, 2017) - de um contexto globalizado e em rede, imediato, incerto e caótico - denominado de modernidade líquida (BAUMAN, 2000) e sob um intenso hiperconsumo e hiperindividualismo (LIPOVETSKY e CHARLES, 2004; LIPOVETSKY e SERROY, 2010) - transformou vertiginosamente, em poucas décadas, a nossa realidade (FEITOZA, 2017; KOPP, 2015).

Em 1973, Daniel Bell preconizava, no seu livro The coming of post-industrial society, um conjunto de novas características que fariam com que a sociedade deixasse de ser orientada por uma economia de produção de bens para entrar numa economia baseada nos serviços. Hoje, o termo "sociedade pós-industrial" já está estabelecido e é unanimemente aceito, tornando-se cada vez menos relevante a consciência da distância entre nós e o objeto físico. Vivemos numa sociedade imaterial e da informação, em que se defende a urgência de nos desenvolvermos numa era do conhecimento, claramente manifestada nas intenções do presidente da associação TED, Chris Anderson (2016).

Se, em datas anteriores à abertura dos mercados, nos anos 1980, os serviços oferecidos não encontravam grande concorrência ${ }^{3}$ - não havendo, por isso, interesse em fazer deles um ponto de diferenciação entre marcas -, hoje a realidade é substancialmente diferente. Vivemos o capitalismo das marcas, em que se multiplicam as escolhas entre múltiplos produtos semelhantes. O mercado passou a oferecer uma espécie de ampliação "aparente" das opções de consumo e produção, sendo que, além disso, quase tudo pode ser rapidamente copiado e com grande qualidade. Na verdade, muitos desses produtos não são capazes de se diferenciarem entre si pelo seu benefício tradicional, exigindo um novo modelo de gestão no nível da criação de valor para a marca. Inovação e capacidade técnica, embora importantes, já não são suficientes. Reconhece-se, portanto, que a marca não pode ser uma mera etiqueta.

3 Mercado onde existia um pequeno número de vendedores para os compradores: serviço local (serralheiro, canalizador), serviço de tendência monopolista (água ou telefones) ou serviço oligárquico (bancos, companhias de seguro). 
Considerando essa abordagem, vamos rever, neste artigo: (i) como se desenvolveu a transição de uma economia industrial baseada na produção de objetos de consumo para a economia baseada na imaterialidade da experiência; (ii) a forma como a marca conseguiu se expandir para se adequar às exigências de um mercado em escala global; e (iii) apontar alguns dos desafios e das dificuldades anunciadas pelos paradigmas contemporâneos, nomeadamente aqueles baseados na ideia de transformação.

\section{Economia de serviços: a intangibilidade do produto}

Antes de a promessa estética do valor de uso desprender-se como embalagem e, por fim, como imagem publicitária, ela já se encontra ativa fora da mercadoria, na boca e nos gestos do vendedor. Uma grande parte das funções da estética da mercadoria, concretamente preenchidas mais tarde, é vista como desempenho pessoal daquele que veste a máscara característica do vendedor (HAUG, 1997, p. 89).

No trecho com que abrimos esta seção, o autor dá conta de como é prévia à estética gráfica e das narrativas de marketing a consciência do manto simbólico transferido para as mercadorias pela performance da pessoa que acompanha/vende o produto. O mercado de serviços ganha, assim, maior impulso no final dos anos 1960, numa crescente tendência comercial e efusividade consumista. Por testemunhá-las, estas se tornam um dos alvos preferenciais das sátiras do ator e realizador francês Jacques Tati, nomeadamente no hilariante filme Playtime, de 1967. 
Figura 1: Frame do filme Playtime

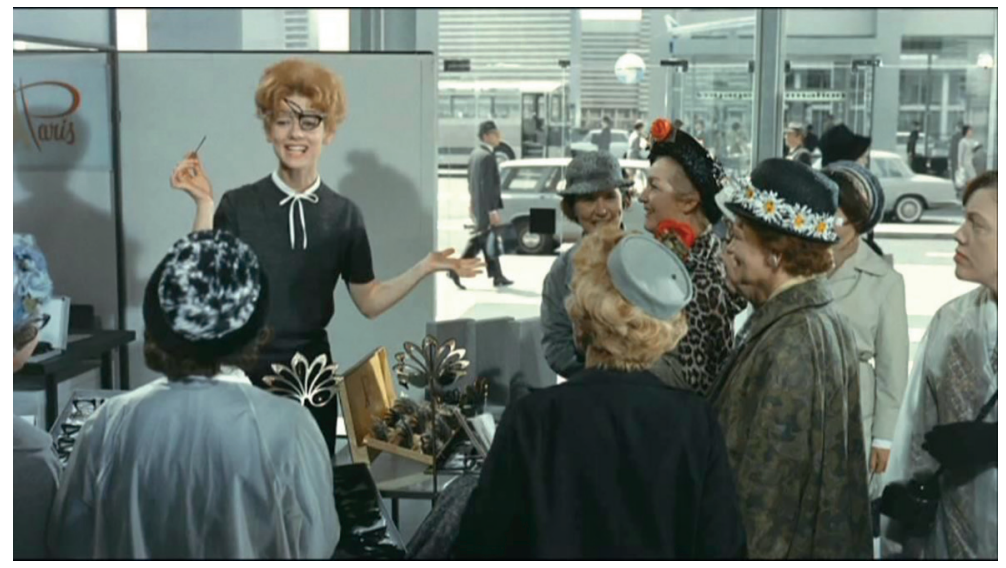

Fonte: arquivo do autor

Fruto das políticas neoliberais dos anos 1970 e 1980, dá-se a “explosão" do mercado e o panorama econômico mundial sofre profundas alterações. Quando os produtos conseguem ser tão bons quanto os concorrentes e com custos semelhantes entre si, é na qualidade do serviço (nomeadamente na pós-venda) que pode residir grande parte do sucesso da marca. Consequentemente, irrompem, no cenário do marketing, as marcas de serviços que exigem qualidades adicionais e uma mudança radical na forma de comunicação dominante até então.

As marcas mais poderosas passam a constar da nossa vida através dos serviços que oferecem, tornando-se tão ou mais importantes que os próprios produtos. Mesmo aquelas que aparentemente se dedicam exclusivamente ao valor da sua performance têm adquirido cada vez mais caraterísticas das marcas de serviços. Como verifica o gestor de marcas Wally Olins:

[...] as opiniões dos médicos sobre os diferentes laboratórios farmacêuticos concorrentes são influenciadas por aquilo que pensam dos delegados [de propaganda médica] que os visitam, para não falar de congressos e de ofertas semelhantes proporcionadas pelos laboratórios (OLINS, 2005, p. 80-82). 
Com o aumento dos setores focados em serviços, é à comunicação da marca que se entrega a importante tarefa de transmitir o caráter da empresa. É através desse trabalho com a marca (branding) que se expõem as "afirmações emocionais" do serviço que, por si só, é imaterial. Na boca e nos gestos do vendedor é comunicada a marca. Assim, o comportamento dos funcionários se torna crucial para confirmar ou não o que a publicidade promete. Como os serviços dependem essencialmente da performance dessas pessoas, a gestão de uma marca de serviços diz respeito à forma como os próprios funcionários vivem e a respiram - o vendedor é, ele próprio, a marca, como defende Wally Olins. É nesse sentido que tal especialista em branding e identidade corporativa reforça a importância de os funcionários serem treinados nos negócios de serviços. Se eles compreenderem a natureza do serviço que prestam, mesmo perante falhas, estarão preparados para um esforço sincero a bem do funcionamento da marca (OLINS, 2005, p. 83).

Segundo a ideologia desse novo modo de administrar, as pessoas que acompanham o produto (funcionários, revendedores, etc.) deixam de ser vistas como empregadas e passam a ser entendidas como colaboradoras. Da mesma forma, também o público começa a ser entendido não como consumidor ou utilizador, mas como um participante nessa relação. Todavia, conforme observa Olins, esse ajuste nem sempre acontece. Segundo o autor, as marcas de serviços "são frequentemente mal geridas" (OLINS, 2005, p. 81) na medida em que continua a vigorar, erradamente, o modelo tradicional aplicado à gestão das marcas de produtos. Poder-se-á afirmar que a tendência desejável para a realização dessa prática passa pela deslocalização do tradicional centro de poder. Nesse contexto, Olins salienta quão exemplar é o modelo praticado pelo banco sueco Svenska Handelsbanken ao buscar complementar a alta tecnologia com o alto relacionamento. No torvelinho das mudanças tecnológicas da nossa era, essa instituição parece ter conseguido "ater-se a uma cultura baseada nos serviços, real, genuína e 'antiquada' - mas agora, claro, extremamente moderna” (OLINS, 2005, p. 89). 
Com o aperfeiçoamento da industrialização e a ampliação da sociedade de consumo, temos acesso a uma grande quantidade de produtos de qualidade e estética semelhantes, pelo que inovação e capacidade técnica, embora importantes, já não são suficientes. Na verdade, muitos desses produtos parecem não diferir muito entre si. A marca passou a desempenhar um papel preponderante para colmatar o vazio provocado pela padronização da produção. Assim, junto com a ideia da marca, o consumidor procura adquirir "um suplemento de alma, de sonho e de identidade" (LIPOVETSKY e SERROY, 2010, p. 117). Através de um trabalho semântico, tenta-se a todo custo restituir aos produtos a identidade que outrora lhes era atribuída pelo artesão ou fabricante. Além disso, vivendo o indivíduo contemporâneo seu ponto máximo de individualidade - ou num hiperindividualismo (LIPOVETSKY e CHARLES, 2004) -, mais do que a utilidade em si, o foco da comunicação recai sobre o que o objeto representa para o utilizador, ou seja, na sua representação: na importância do que possui-lo significa para si e, essencialmente, o que possuir esse objeto vai significar para si perante os outros. Esse fenômeno levou a uma mudança radical na forma de se comunicar:

$[\ldots]$ já não se trata de martelar uma mensagem a elogiar os benefícios objetivos do produto [...]. Trata-se de inovar, surpreender, divertir, fazer sonhar, comover, criar um mito, o que se consegue com a utilização de efeitos especiais, de imagens sublimes, de jogos de ritmo e de montagem. Estamos muito longe do bom e velho anúncio behaviorista. Em muitos aspetos tomou Hollywood como modelo (LIPOVETSKY e SERROY, 2010, p. 118-119).

\section{A cultura-mundo e a hipermarca}

Poderíamos perguntar se a dimensão estética e criativa não terá sido sempre crucial dentro do universo capitalista. A resposta é afirmativa. A função estética baseada na epiderme do produto foi, desde cedo, um aliado fundamental das vendas, promovendo e fazendo destacar 
determinado produto da sua concorrência. Contudo, no mundo globalizado de hoje, o fator estético torna-se primordial em uma escala completamente nova. Já não se trata de produzir formas que lembrem as correntes artísticas, de chamar os artesãos para virem embelezar os objetos no final da linha de produção, tampouco de basear o projeto unicamente na estética resultante da relação forma/função.

À medida que a sociedade de consumo evoluiu, transformou por completo a noção de cultura. Se, por um lado, a cultura que se afirma nova e de elite é absorvida e colonizada pelo mercado e pela cultura midiática, por outro, os bens comerciáveis constituem atualmente uma cultura de um gênero novo - no que Lipovetsky e Serroy (2010, p. 86) denominam de "cultura-mundo". Ou seja, nesse contexto global, o que é comercializável tenta se posicionar como obra cultural, procurando integrar, de alguma forma, os princípios criativos e estéticos da alta cultura. Ainda que existindo uma relação tensa entre cultura e economia, pela ideia de que hoje vivemos num mundo de homogeneização mercantil e onde "tudo é cultura" (conforme a própria definição de cultura-mundo), a esfera artística não rejeita, contudo, as regras do mercado. Na verdade, tem permitido que a arte, após ser envolvida nos valores do mercado, se torne um fator fundamental na estetização do quotidiano e do mundo, sendo um fenômeno batizado de "artialização do mundo" por Lipovetsky e Serroy (2010, p. 124). Numa entrevista, Lipovetsky afirma que, hoje, "uma marca não vende apenas um produto, vende uma cultura, um estilo de vida. Contratam-se designers, publicitários, criativos, que investem mais na marca do que no produto", sendo que essa representação "é a cultura” (MARIANO, 2010). Passa-se para uma nova dimensão da ideia de marca - a hipermarca (LIPOVETSKY e SERROY, 2010) - na medida em que se faz um investimento maior na sua condição imaterial, desenvolvendo seu nível simbólico através do marketing. Como exemplo, podemos identificar a campanha publicitária "Ser português é nobre" (2018). A mensagem para essa marca de charcutaria e enlatados portuguesa assenta no orgulho nacional, conferindo aos portugueses a responsabilidade pelas mudanças e melhorias contemporâneas verificadas no país. 
A necessidade de se chegar ao público de uma nova maneira estimulou a formação de equipes criativas com natureza híbrida. Por todo lado se assiste à tendência de projetos que nascem de sinergias provenientes de diversos campos que cruzam e desafiam todas as fronteiras através da fusão de muitas possibilidades. Como consequência, tornou-se cada vez mais frequente a colaboração de artistas e designers com arquitetos em espaços comerciais ou de grandes realizadores de cinema em anúncios publicitários com intuito comercial. Com um caráter híbrido, salientamos a colaboração do famoso cineasta chinês Wong Kar-Wai, que foi convidado para divulgar comercialmente a marca BMW, realizando The Follow (2001), terceiro filme encomendado para a série "The Hire"; e que realizou o curta-metragem Déjà Vu (2012) para o uísque Chivas Regal. A frequência com que essas colaborações acontecem atualmente e a qualidade que resulta de algumas dessas aventuras nos levam a concordar com os sociólogos Lipovetsky e Serroy quando defendem que “o importante não é que seja 'grande' arte ou arte comercial. Apenas importa o que é realizado, a obra em si mesma” (2010, p. 124).

\section{Economia da experiência: a memória da marca}

Essa mudança de paradigma, desencadeada a partir de meados dos anos 1980, deve-se, segundo Wally Olins (2005), à combinação de três fatores: a desregulamentação do mercado, a globalização e a incidência cada vez maior das novas tecnologias no quotidiano. A confluência dessas três condições e o acesso democrático às tecnologias fizeram com que a concorrência se tornasse cada vez mais feroz. Tal como explica Olins (2005, p. 8):

Nos dias de hoje, porque as tecnologias mais modernas se encontram à disposição de toda a gente, todos os concorrentes de topo em qualquer área são muito bons. Na realidade, para se poder entrar na corrida é necessário ser-se tão bom quanto os melhores. [...] E se todos os competidores forem bons, ganha aquele que tiver melhor reputação. 
Para sobreviverem, as marcas se viram na necessidade de serem mais do que meras etiquetas, passando a alimentar um universo que se expande em museus, jogos, filmes, séries televisivas e se prolongam em discussões na esfera virtual.

O pioneiro dessa atitude publicitária foi o fotógrafo Oliviero Toscani, nos anos 1980, ao dirigir a campanha "United colors of Benetton". Pela primeira vez, uma marca de roupa se apresenta num suporte publicitário convencional mostrando comportamentos sociais e a condição humana em geral em situações fraturantes da década ou suficientemente polêmicas para não passarem indiferentes à indignação e reflexão públicas. Através de questões sobre racismo, Aids, política ou religião, levanta-se a pergunta se a publicidade pode ou não ter uma função de crítica e denúncia social. Com a atitude desse fotógrafo, difunde-se uma nova noção de marca que leva mais além sua função, que é de identificação e diferenciação do produto em relação aos seus concorrentes. Os cartazes daquela marca de roupa italiana, muitas vezes rejeitados pelo incômodo das suas provocações, manifestavam uma ousadia próxima dos objetos de arte e foram apresentados na reconhecida Bienal de Veneza de arte contemporânea em 1993 (Aperto ‘93).

Hoje, ao valor da reputação que a marca comunica sobre seus produtos e serviços, importam cada vez mais fatores ligados ao entendimento que o público faz dessa mesma reputação. Já não basta à marca ser melhor do que as concorrentes, tem de ser vista como sendo a melhor (OLINS, 2005, p. 257). Nessa sua perspetiva sobre a presença da marca no mercado atual, Wally Olins esclarece que mais importante do que aquilo que as marcas fazem é o modo como fazem. E mais importante ainda é a forma como são percebidas que o fazem (OLINS, 2005, p. 8) e o seu investimento na autenticidade. Podemos verificar como na marca Ferrari, considerada uma das mais poderosas do mundo pela Brand Finance (LIMAS, 2013), a intuição das pessoas ultrapassa a noção de produto físico em si e até sua utilização:

[...] esta marca não investe um único centavo em publicidade, e continua a ser uma das marcas mais admiradas e valorizadas em todo o mundo. 
[...] A maioria dos entusiastas da Ferrari não têm um Ferrari, e possivelmente jamais alcancem esse sonho [...]. O seu logótipo inspira poder, luxo e sofisticação; uma mistura de velocidade selvagem e delicadeza italiana. A casa de Maranello posicionou seus carros na imaginação de pessoas no mundo, e tudo isso graças a uma história tão comovente como feroz (LIMAS, 2013).

Wally Olins reconhece que é fundamental um trabalho no nível da gestão da marca (branding) não só para destacar as suas diferenças, mas também para mostrar intensamente essas diferenças no mercado através de atitudes próprias. Porém, torna-se fundamental nesse processo uma história mais baseada em ações consistentes e relevantes do que apenas na construção de aparências ligadas à produção material. A identidade de uma marca que se estrutura sobre determinados valores terá de ser trabalhada para manter a coerência entre aquilo que anuncia e aquilo que pratica na realidade, estando cada vez mais sujeita ao escrutínio de pessoas mais informadas. São exemplos dessa crescente sensibilidade do cidadão os movimentos e atitudes anticapitalistas das últimas duas décadas - como o livro No Logo, de Naomi Klein (2002) ou ntes envolvem com sucesso o Walli Olinsansformaç -, que se revelam contra a marca enquanto símbolo das dramáticas explorações laborais, da distribuição desigual da riqueza e do desperdício incalculável de recursos finitos. Na era da informação em rede, o perfil do novo consumidor revela maior inquietação e maior disponibilidade para lutar contra a ditadura das grandes marcas. Um exemplo paradigmático dessa posição é relatado no documentário Comprar, tirar, comprar. La história secreta de la obsolescencia programada (2010), sobre consumidores que, no ano de 2003, ganham uma causa judicial contra a empresa Apple. Essa luta foi despoletada pela ação organizada de dois irmãos videoartistas (The Neistat Brothers) que não se resignaram com o fato de a bateria de seu iPod ter vida útil de apenas 18 meses. Como protesto, fizeram circular

4 Essa pesquisadora revela e analisa intensamente problemas originados pela subversão da sociedade de consumo. Desde sua primeira edição, parece alimentar movimentos políticos antiglobalização. 
um pequeno vídeo pela rede de contatos que se tornou viral, conseguindo chamar atenção para sua questão numa escala gigantesca.

Olins defende que, hoje, o potencial de uma marca pode ultrapassar a função de influência, estratégia ou tática comercial que beneficia, quase de forma cega, os objetivos capitalistas supremos. Esse autor defende que o modelo de gestão da marca pode ser orientado para beneficiar outros fins - como as artes, o desporto, a educação, a saúde e outras áreas sociais - como forma de encorajar as pessoas a desenvolverem uma relação estreita com atividades genuinamente importantes e meritórias (OLINS, 2005).

Nesse processo de imaterialização, foi-se gradualmente compreendendo que, para as empresas, a produção de um objeto de consumo é apenas parte do negócio. É com essa consciência que muitas marcas atualmente desenvolvem com sucesso o branding e o marketing de experiência (BRAKUS, SCHMITT e ZARANTONELLO, 2009) - de interação e proximidade, estimulando permanentemente nossos desejos e entendendo o funcionário e a audiência como referências fundamentais no processo de comunicação. Em 2012, a marca norte-americana de cafés Starbucks já aplicava vivamente esse modelo, como apresentou em conferência sua diretora de marketing à época, Beatriz Jiménez-Asenjon.

Investigações realizadas por personalidades de referência como Joseph Pine e James Gilmore têm contribuído para uma análise inovadora no campo da economia que apresenta a passagem de uma lógica de serviços para uma lógica de experiência. Nessa transição, os autores reconhecem que o valor comercial deixou de depender de um conceito tradicional de serviço para se basear na oferta de experiências memoráveis e de prazer criadas com essa mesma intenção. Os autores identificam a Disney como a pioneira dessa mudança. Desde a primeira edição de seu influente livro The experience economy (1999), defendem que "os bens e os serviços já não são suficientes” e apontam para uma inevitável mudança. Dizem ser necessário "abandonar velhos paradigmas de Economia Industrial e de Serviços a fim de introduzir novas experiências e transformações”. Para além disso, argumentam que, para um mundo 
saturado de bens e serviços, "reconhecer a experiência como uma oferta econômica distinta fornece a chave para o crescimento econômico futuro" (PINE e GILMORE, 2011, p. IX-XXIV). Segundo os autores, essa mudança implica passar da mentalidade do "que" (what) para o "como" (how). Ou seja, já não é suficiente pensar apenas no design e na produção das coisas, mas transformar as interações mundanas em relações evolventes para atingir a "sensibilidade interativa" do cliente (PINE e GILMORE, 2011, p. 25).

Tal como demonstramos em publicações anteriores (DIAS e MOURA, 2017; DIAS, 2017), o mesmo apelo - reequacionar a visão insuficiente e unidimensional que se concentra no objeto em si - tem sido feito por diversos autores. Para o arquiteto Teddy Cruz (2010), a sociedade tem perpetuado a ideia de belo como algo de mágico inerente ao objeto e não como uma noção que advém de uma relação na qual participamos verdadeiramente. Ou seja, a estética é entendida como uma coisa (o "que") e não como uma relação (o "como"), dificultando, segundo o arquiteto, o abandono desse paradigma modernista ao perpetuá-lo socialmente (CRUZ, 2010). Todavia, ao longo de nossa pesquisa de doutorado (DIAS, 2015), demo-nos conta de que, cada vez mais, são os pensadores, vindos de diversas áreas, que parecem comprovar a tese de uma tendência relacional, ${ }^{5}$ defendendo uma revisão crítica dos paradigmas estabelecidos e abrindo a discussão para a teoria das relações.

Perceber a qualidade das relações ou do envolvimento do utilizador durante o processo de interação desencadeou um conjunto de novas questões que vão além dos aspectos puramente utilitários. E é nesse contexto que se tem reclamado uma revisão de todos os "fantasmas" que foram excluídos pela visão modernista da linearidade histórica dos acontecimentos. Essa consciência parece estar presente na crescente sensibilidade para com os valores da identidade da "pessoa comum", suas histórias e ações como significativos pilares da civilização. Note-se esse fenômeno em iniciativas comerciais como o chamado "mercado

5 A esse propósito, salientamos Frank Popper (1997), Claire Bishop (2004), Grant Kester (2011), Nicolas Bourriaud (1998), Andrew Blauvelt (2008) e Meike Schalk (2011). 
da saudade”. Na área da pesquisa, recorre-se cada vez mais à inspiração no quotidiano e nos comportamentos humanos e à discussão sobre a importância da "sensorialidade" da experiência. Abalam-se, dessa forma, pressupostos de uma análise objetivamente pura, como se pode constatar no livro Doing sensory ethnography (2009), da antropóloga Sarah Pink, ou em diversos exemplos no mundo da arte e do design, como as coreografias de Pina Bausch; projetos com base na estética relacional (segundo o conceito de Nicolas Bourriaud); ou em metodologias flexíveis como o design thinking. São inúmeras as produções da atualidade que manifestam essa viragem cultural, em que o processo assume maior centralidade do que o resultado final. Assumindo pensar a cultura através do corpo e dos sentidos, a experiência é vivida não só pelos agentes pesquisados, mas também permitida ao próprio "pesquisador". A mesma viragem parece se dar no nível da economia, no qual encontramos termos emergentes como economia da experiência e economia da transformação (PINE e GILMORE, 2011).

Contrariando a relação tensa que se vive entre a cultura e a economia, numa ideia de que hoje vivemos em um mundo de homogeneização mercantil - em que "tudo é cultura" e da percepção polêmica de que a cultura pode ser qualquer coisa sem qualquer virtude - e de perda simbólica, Lipovetsky e Serroy (2010, p. 157) defendem a tese de que essa situação tem, pelo contrário, gerado uma reação no âmago do problema. Esses intérpretes sociais acreditam que estamos vivendo uma "vingança cultural" "[...] a fim de contrariar o sentimento de perda de si".

Podemos, assim, considerar que a procura de sentido é um mecanismo de defesa em resposta à nossa circunstância histórica e que valores como autenticidade, empoderamento da pessoa comum e as relações envolventes são o foco das intenções mundanas e comerciais para o reposicionamento de algumas marcas no mercado. Veja-se a recente comunicação global da marca Vodafone, em anúncios como "The story of Hello" ou "Instalação" (2017/2018). 


\section{Da economia da experiência à economia da transformação}

Reportando-nos ainda à tese defendida por Pine e Gilmore, julgamos importante referir que os autores vão além do modelo de mercado baseado na experiência ao reconhecer que "as experiências não são a última oferta econômica” (PINE e GILMORE, 2011, p. 244). Argumentam que, com o tempo, tampouco ela deixará de se tornar uma mercadoria, uma vez que uma experiência repetida perde sua eficácia de envolvimento e de sedução. Defendem que as pessoas, mais do que perseguir uma experiência e sua participação ativa, parecem desejar algo superior:

Queremos transformar-nos, tornarmo-nos diferentes. Enquanto que as experiências são menos transitórias do que os serviços, a coparticipação individual na experiência muitas vezes quer algo mais duradouro do que uma memória, algo além do que qualquer bem, serviço ou experiência por si só pode oferecer (PINE e GILMORE, 2011, p. 242-243).

Segundo os autores, uma experiência se torna automaticamente uma "transformação" quando é personalizada para um indivíduo concreto, promovendo, no momento certo, aquilo de que ele mais precisa. Tal como a "experiência" é um fenômeno que consideram estar no topo dos serviços, a "transformação" é um fenômeno que aparece no topo da experiência. Podemos visualizar esse encadeamento da progressão do valor econômico na Figura 2: 
Figura 2: Elevando a progressão do valor econômico: esquema desde uma economia agrária até a economia da transformação segundo Joseph Pine e James Gilmore

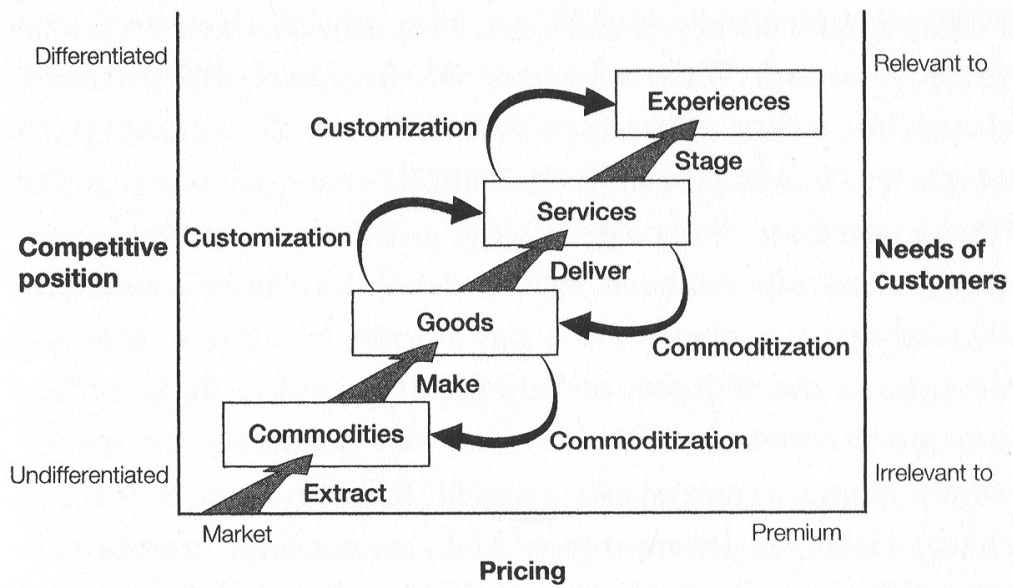

Fonte: Pine e Gilmore (2011, p. 111)

Conforme podemos analisar no esquema dos autores, o valor econômico que resulta da economia da transformação não é o extraído da tangibilidade do produto (como acontece na economia agrária), da imaterialidade do serviço ou da memória da experiência. Esse valor provém, antes, da "transformação individual". A consequência da oferta comercial dessa última fase vai para além do consumo, uma vez que, quando uma empresa orienta transformações, a oferta é o indivíduo - assim o defendem Pine e Gilmore (2011, p. 255).

Os autores consideram que essa mentalidade está cada vez mais presente nas indústrias que se entendem como parte do setor de serviços. Como exemplo dessa consciência, mencionam a entrevista ao formador John Quelch, da London Business School:

Nós não estamos no negócio de educação. Estamos no negócio de transformação. Esperamos que todos que participam num Programa da London Business School - quer seja por três dias ou por dois anos - sejam transformados pela experiência (PINE e GILMORE, 2011, p. 248). 
Todavia, para os autores, o modelo que denominam de economia da transformação só encontrará condições para avançar nas próximas décadas quando a economia da experiência terminar o seu curso. Tal como aconteceu com a economia da experiência, dizem, será necessário um longo período de adaptação, uma vez que ambos os modelos transportam consigo um novo vocabulário (como "produtos intangíveis") que requer algum tempo de assimilação. $\mathrm{O}$ mesmo se verificou com o termo economia de serviços, atualmente generalizado.

\section{Considerações finais}

Julgamos que a pertinência das novas abordagens aqui referidas, provenientes de diversas áreas de conhecimento, como a economia, o design e o marketing, parecem emergir ante a necessidade de se encarar um ambiente em constante mudança. A par das manifestações práticas no terreno, as mais recentes linhas de investigação têm igualmente revelado que uma tendência com foco no ser humano (no seu comportamento, na participação, experiência e transformação) e na necessária capacidade de ver tudo em relação (como um ecossistema interativo) é crucial para conquistar as expectativas do "consumidor". Tal como referido, o termo transformation design tem emergindo intuitivamente do deslocamento de uma lógica de serviços "de procurar dar resposta a problemas específicos" para uma lógica "de fornecer às organizações as ferramentas e as capacidades para um serviço de inovação centrado no ser humano" (SANGIORGI, 2011, p. 31). Os padrões (metodológicos, contextuais e mesmo filosóficos) provenientes dessas novas abordagens se mostram suficientemente distintos dos tradicionais para se acreditar que estamos diante de um potencial de mercado suficientemente significativo para que nele se faça investimento. Para Pine e Gilmore (2011, p. 255), o sucesso das empresas e das marcas residirá na capacidade de compreender as "aspirações dos consumidores individuais e empresas, orientando-os para realizar plenamente essas aspirações”.

Devemos, no entanto, questionar até que ponto se pode comprar ou negociar o processo transformativo, uma vez que tem de haver um 
envolvimento intrapessoal e profundamente reflexivo para que essa transformação ocorra, para além da dimensão social que se tem de observar (MEZIROW, 2000). Inclusive, transformação implica mudanças fundamentais quanto a ideias, pontos de vista ou valores dos indivíduos. Será, então, que não terá de haver maior reflexão e discussão sobre os mecanismos usados numa economia da transformação e seu impacto ético, nomeadamente para o futuro da sociedade?

Continuamos a questionar: na era em que vivemos, com o impressionante potencial tecnológico de empoderar qualquer indivíduo na realização plena das suas aspirações, independentemente da moralidade das suas convicções, não deveríamos estar todos em alerta total? Não deveria ser uma preocupação de toda e qualquer área impulsionar uma participação social mais informada, proativa e responsável - também na senda do que Dias, Guareschi e Hennigen (2017) preconizam?

Esperando-se das áreas relacionadas com a comunicação das marcas, como o design e o marketing, uma ação catalisadora de boas práticas e, ao mesmo tempo, impulsionadora da economia, torna-se imperativo pensar essas preocupações num contexto pedagógico: de que forma elas têm moldado o ensino dos futuros profissionais?

\section{Referências}

ANDERSON, C. TED Talks - O guia oficial TED para falar em público. Lisboa: Temas \& Debates, 2016.

BAUMAN, Z. Liquid modernitiy. Cambridge: Polity Press, 2000.

BELL, D. The coming of post-industrial society. Nova York: Basic Books, 1973.

BISHOP, C. Antagonism and relational aesthetics. October Magazine. Cambridge: MIT Press, n. 110, p. 51-79, 2004.

BLAUVELT, A. Towards relational design. Design Observer-Observatory. 11 fev. 2008. Disponível em: https://designobserver.com/feature/towards-relational-design/7557. Acesso em: fev. 2011.

BOURRIAUD, N. Relational aesthetics. Dijon: Les Presses du Réel, 2002. (trabalho original publicado em 1998). 
BRAKUS, J. J.; SCHMITT, B. H.; ZARANTONELLO, L. Brand experience: what is it? How is it measured? Does it affect loyalty? Journal of Marketing, v. 73, p. 52-68, maio 2009.

BROWN, T.; KATZ, B. Change by design: how design thinking transforms organizations and inspires innovation. Nova York: Harper Collins, 2009.

COMPRAR, TIRAR, COMPRAR. La história secreta de la obsolescencia programada. Direção: Cosima Dannoritzer. Produção: C. Media 3.14 \& Article Z. Espanha; França, 2010. Disponível em: http://www.rtve.es/alacarta/videos/el-documental/documental-comprar-tirar-comprar/1382261/. Acesso em: jul. 2018.

CRUZ, T. Relational Aesthetics. In: CONVERSATIONS ON BEAUTY: beauty and the built environment. Anais... [s. 1.], 2010. Disponível em: http://www.youtube.com/ watch?v=pfVaV6ZNQ-M. Acesso em: 12 maio 2013.

DÉJÀ VU. Direção: Wong Kar-Wai. Produção: Jet Tone Films. Hong Kong, 2012. Curta-metragem (72 s). Disponível em: https://www.imdb.com/title/tt2565622/?ref_=rvi_tt. Acesso em: 5 set. 2018.

DIAS, D. D.; GUARESCHI, P. A.; HENNIGEN, I. Reflexões sobre o viver e a politização das práticas de consumo. Comunicação, Mídia e Consumo. São Paulo: ESPM, v. 14, n. 39, p. 31-49, 2017.

DIAS, S. Design como processo: uma reflexão sobre a dimensão lúdica, participativa e relacional. 2015. Tese (doutorado em Arte e Design) - Faculdade de Belas Artes, Porto, Portugal, 2015. 300f.

O momento presente e os novos contornos culturais - reflexões para a área do design. Convergências - Revista de Investigação e Ensino das Artes. Castelo Branco, Portugal, v. 10, n. 20, 2017.

. Reflexão sobre o papel do designer contemporâneo - o desajuste entre a teoria e a prática no ensino do Design. Convergências - Revista de Investigação e Ensino das Artes. Castelo Branco, Portugal, v. 11, n. 21, 2018.

.; MOURA, M. Aspetos do mundo contemporâneo e a tendência relacional no design: uma síntese. In: UD'17 NOISEWISE - Design Research in face of current challenges to knowledge. Annual Forum on Doctoral Design Research, 6., 2017, Porto. Anais... Porto: Universidade do Porto, Faculdade de Belas Artes, 2017. p. 16-17.

FEITOZA, F. A gestão do estranhamento e figuras de corporeidade na era estética do capitalismo. Comunicação, Mídia e Consumo. São Paulo: ESPM, v. 14, n. 40, p. 10-24, maio-ago. 2017. Disponível em: revistacmc.espm.br/index.php/revistacmc/issue/download/49/pdf_85. Acesso em: 3 ago. 2018.

HAUG, W. Crítica da estética da mercadoria. São Paulo: Unesp, 1997.

INSTALAÇÃO. Portugal: Vodafone Portugal, 2018. Curta-metragem (30 s). Disponível em: https://www.youtube.com/watch?v=RFfb2SecZGc. Acesso em: 3 set. 2018.

JIMÉNEZ-ASENJO, B. N. Brand experience management: el caso Starbucks. In: HOY ES MARKETING, 9., 2012, Madri. Anais... Madri: Esic Business \& Marketing School, 2012. Disponível em: https:/www.youtube.com/watch?v=qLvwBX7LohI. Acesso em: 19 abr. 2012. 
KESTER, G. H. The one and the many: contemporary collaborative art in a global context. Durham, Carolina do Norte, EUA: Duke University Press, 2011.

KLEIN, N. No Logo. Londres: Flamingo, 2000.

KOPP, R. Design gráfico cambiante para marcas hipermodernas. Comunicação, Mídia e Consumo. São Paulo: ESPM, v. 12, n. 34, p. 124-145, maio-ago. 2015. Disponível em: revistacmc.espm.br/index.php/revistacmc/article/download/925/pdf_70. Acesso em: 5 ago. 2018.

LIMAS, J. C. La marca más poderosa del mundo. Foroalfa, 30 nov. 2013. Disponível em: http://foroalfa.org/articulos/la-marca-mas-poderosa-del-mundo. Acesso em: 3 jul. 2014.

LIPOVETSKY, G.; CHARLES, S. Os tempos hipermodernos. São Paulo: Barcarolla, 2004.

LIPOVETSKY, G.; SERROY, J. Cultura-mundo: resposta a uma sociedade desorientada. Lisboa: Edições 70, 2010.

MARIANO, F. Gilles Lipovetsky: hoje, há demasiado de tudo. Jornal de Notícias, 4 abr. 2010. Disponível em: http://www.jn.pt/Domingo/interior.aspx?content_id=1535438. Acesso em: 2 abr. 2011.

MEZIROW, J. Learning to think like an adult: core concepts of transformation theory. In: _. et al. (Eds.). Learning as transformation: critical perspectives on a theory in progress. São Francisco: Jossey-Bass, 2000.

OLINS, W. A marca. Lisboa: Verbo, 2005.

PINE, J. What consumers want. In: TED2004. Anais... [s. 1.], 2004. Disponível em: https://www.ted.com/talks/joseph_pine_on_what_consumers_want\#t-843429. Acesso em: set. 2018.

PINE, B. J.; GILMORE, James H. The experience economy. Massachusetts: Harvard Business Review Press, 2011.

PINK, S. Doing sensory ethnography. Londres: Sage, 2009.

PLAYTIME. Direção: Jacques Tati. Produção: Jacques Tati. França, 1967. 1 DVD (165 $\min )$.

POPPER, F. Art of the Electronic Age. Thames and Hudson, 1997.

SANGIORGI, D. Transformative services and transformation design. International Journal of Design, v. 5, n. 2, ago. 2011. Disponível em: http://www.ijdesign.org/index.php/ IJDesign/article/view/940/344. Acesso em: jun. 2014.

SER PORTUGUÊS É NOBRE. Direção: Rita Salvado. Produção: Agência McCann. Portugal, 2018. Curta-metragem (1 min). Disponível em: https://www.youtube.com/ watch?time_continue $=1 \& \mathrm{v}=\mathrm{ekfFTfKnCrk}$. Acesso em: set. 2018.

SCHALK, M. Relational aesthetics and institutional change. In: ALTERATION. Session 1. Theories. Anais... Estocolmo: KTH School of Architecture, ago. 2011. Disponível em: https://www.youtube.com/watch?v=CVggSyV8t8o. Acesso em: 12 jun. 2013. SILVA, Marco. O futuro segundo a Vodafone. Imagens de Marca, 5 out. 2017. Disponível em: http://imagensdemarca.sapo.pt/atualidade/o-futuro-segundo-a-vodafone. Acesso em: 3 ago. 2018 . 
THE HIRE: The Follow. Direção: Wong Kar-Wai. Produção: Anonimous Content; BMW Film. Hong Kong, 2001. Curta-metragem (527 s). Disponível em: https://www. youtube.com/watch?v=rIHGT8vWleQ. Acesso em: 5 set. 2018.

THE STORY OF HELLO. Direção: Caspar Balslev. Produção: Ridley Scott Associates. [s. 1.], c. 2018. Curta-metragem (1 min). Disponível em: http://artofficialagency.com/ composers/martin-dirkov/vodafone-the-story-of-hello/. Acesso em: 3 set. 2018.

\section{Sobre as autoras}

Carla Suzana Dias - Professora adjunta do Departamento de Arte e Comunicação da Escola Superior de Design (IPCA-ESD) no curso de licenciatura em Design Gráfico. Doutora em Arte e Design pela Faculdade de Belas Artes da Universidade do Porto (FBAUP, 2015).

Ana Baptista - Conselheira de ensino e aprendizagem. Doutora pela Universidade de Aveiro, Portugal, em Ciências Educacionais. Docente na Queen Mary University of London.

Data de submissão: 24/09/2018

Data de aceite: 24/02/2019 